\title{
USO DA ANÁLISE DE COMPONENTES PRINCIPAIS PARA AGRUPAMENTO DE AMOSTRAS DE SOLOS COM BASE NA GRANULOMETRIA E EM CARACTERÍSTICAS QUIIMICAS E MINERALÓGICAS
}

\section{USE OF PRINCIPAL COMPONENT ANALYSIS FOR GROUPING SOIL SAMPLES BASED ON PARTICLE SIZE AND CHEMICAL AND MINERALOGICAL CHARACTERISTICS}

\author{
Larissa KUMMER ${ }^{1}$ \\ Vander de Freitas MELO ${ }^{2}$ \\ Yara Jurema BARROS ${ }^{3}$ \\ Julio César Rodrigues AZEVEDO ${ }^{4}$
}

\begin{abstract}
RESUMO
São vários fatores que determinam as variações horizontais e verticais nos atributos químicos, físicos e mineralógicos dos solos. Assim, objetivou-se aplicar a técnica de análise por componentes principais (ACP) para verificar a similaridade de amostras de solos em uma área, com base na granulometria e em seus atributos químicos e mineralógicos, e estabelecer relações com o material de origem, profundidade do solo e interferências antrópicas. Coletaram-se amostras em três profundidades $(0-10 \mathrm{~cm} ; 10-20 \mathrm{~cm}$ e $20-40 \mathrm{~cm})$ de 8 locais distintos dentro de uma área de extração e beneficiamento de metais pesados, no município de Adrianópolis-PR. Foram determinados a granulometria e os atributos da fertilidade dos solos. A fração argila foi estudada por difratometria de raios $\mathrm{X}$, análises térmicas e extrações químicas com oxalato de amônio e ditionito-citrato-bicarbonato. Com base nos resultados geraram-se duas ACP, uma com a granulometria e os dados químicos e outra com os mineralógicos. A primeira demonstrou que o material de origem associado à incorporação de resíduos da metalurgia de metais pesados aos perfis de solo foram determinantes para o agrupamento das amostras. Já a segunda, discriminou as amostras do solo alóctone (sedimentos coluvionares), mas, devido à similaridade da mineralogia da fração argila, não separou solos com diferentes graus de desenvolvimento (Neossolos e Cambissolos). Os teores de hematita, se contrapondo aos teores de goethita, mais os teores de gibbsita, foram preponderantes para o agrupamento das amostras. Desta forma, recomenda-se a utilização da ACP para discriminar solos nas condições do presente estudo.

Palavras-chave: mineralogia; análise multivariada; mineração de metais pesados.
\end{abstract}

\begin{abstract}
There are several factors that determine the horizontal and vertical variation in the chemical, physical and mineralogical soil attributes. The objective was to apply the technique of principal component analysis (PCA) to verify the similarity of soil samples in an area, based on particle size and their chemical and mineralogical characteristics, and establish relations with the source material, soil's depth and antropic interferences. Samples were collected at three depths $(0-10 \mathrm{~cm}$, $10-20 \mathrm{~cm}$ and $20-40 \mathrm{~cm}$ ) from eight different locations within an area of extraction and processing of heavy metals in the city of Adrianópolis-PR. Texture and the attributes of soil fertility were determined. The clay fraction was studied by X-ray diffraction, thermal and chemical extractions with ammonium oxalate and dithionite-citrate-bicarbonate. Based on the results, two PCA were generated, one with particle size and chemical data and another with mineralogic data. The first showed that the parent materials associated with the incorporation of heavy metal metallurgy wastes in soil profiles were determinant in grouping the samples. The second PCA separated allochthonous soil samples (colluvium sediments), but given the similarity of clay mineralogy, couldn't not separated soils with different degrees of development (Entisols and Inceptisol). The concentration of hematite, contrasting to the contents of goethite, in addition to gibbsite levels, were predominant in the grouping of the samples. Thus, the use of PCA was recommend to discriminate soils in the conditions of the present study.
\end{abstract}

Key-words: mineralogy; multivariate analysis; heavy metal mining.

\footnotetext{
${ }^{1}$ Professora do Curso de Engenharia Ambiental, Universidade Tecnológica Federal do Paraná - UTFPR. Linha Santa Bárbara, s/n, CEP 85601971, Francisco Beltrão, PR, Brasil. E-mail: Ikummer@utfpr.edu.br

${ }^{2}$ Professor do Departamento de Solos e Engenharia Agrícola, Universidade Federal do Paraná - UFPR. Rua dos Funcionários, 1540, CEP 80035-050, Curitiba, PR, Brasil. Bolsista CNPq. E-mail: vanderfm@ufpr.br. Autor para correspondência.

${ }^{3}$ Mestre em Ciência do Solo, Universidade Federal do Paraná - UFPR. Rua dos Funcionários, 1540, CEP 80035-050, Curitiba, PR, Brasil. Email: yarajuba@gmail.com

${ }^{4}$ Professor do Departamento de Química e Biologia, Universidade Tecnológica Federal do Paraná - UTFPR. Curitiba, PR, Brasil. E-mail: jcrazevedo.utfpr@gmail.com
} 
KUMMER, L. et al. Uso da análise de componentes principais...

\section{INTRODUÇÃO}

As alterações, transformações $\mathrm{e}$ neoformações de minerais que ocorrem no ambiente do solo no decurso da intemperização são condicionadas por numerosos fatores físicos, químicos e biológicos, como mudanças locais de umidade, absorção, lixiviação, atividade biológica e $\mathrm{pH}$ (White \& Brantley, 1995). Como resultado, o solo pode ser bastante heterogêneo, mesmo em locais considerados próximos (Barbar \& Melo, 2008). Diversos estudos mostraram a existência de grandes variações nos atributos químicos do solo em uma curta distância horizontal (Kitchen et al., 1990; Wollenhaupt et al., 1994). Em contraste com os diversos trabalhos na área de fertilidade do solo, são poucos os estudos de variações de características mais estáveis no solo, como a mineralogia das frações areia, silte e argila, para uma mesma área, em função do local de amostragem (variação horizontal). Barbar \& Melo (2008) estudaram as variações nos teores totais de elementos e na mineralogia das frações mais finas do solo em curtas distâncias horizontais dos horizontes A e B de Cambissolos (amostragem composta por quadrante) em cinco áreas na Região Metropolitana de Curitiba. Os valores dos coeficientes de variação (CV) entre as repetições tomadas a curtas distâncias horizontais foram inversamente proporcionais à estabilidade da característica do solo analisada. Menores valores de $\mathrm{CV}$ foram encontrados para os teores totais de $\mathrm{Fe}_{2} \mathrm{O}_{3}$ e $\mathrm{Al}_{2} \mathrm{O}_{3}$ (CV entre 0,9 a $14,2 \%$ ) e teores de minerais de alta cristalinidade (caulinita e gibbsita) (CV entre 1,8 a 17,5\%); comportamento oposto foi verificado para os óxidos de $\mathrm{Fe}$ e $\mathrm{Al}$ de baixa cristalinidade (CV entre 6 a 109,7\%).

Nesse contexto, as análises de distribuição espacial, considerando as diferentes paisagens dos solos pelo uso da estatística multivariada, têm sido amplamente utilizadas por poder contribuir no melhor entendimento do ambiente (Boruvka \& Kozak, 2001). A análise de componentes principais (ACP) pode ser usada para identificar e quantificar a variação do solo associada a diferentes processos pedogenéticos (Carvalho Junior et al., 2008).

Este tipo de análise é usado para transformar os dados para duas dimensões e, assim, fazer uma estimativa da similaridade dos dados (Goloboèanin et al., 2004). A ACP é uma técnica que indica as associações entre variáveis reduzindo, assim, a dimensão do número de dados e agrupando aquelas com maior similaridade (Santos et al., 2008; Valladares et al., 2008).

Splechtna \& Klinka (2001) estudaram solos florestais em uma região montanhosa do Canadá e utilizaram a análise de componentes principais para examinar as relações entre regimes de nutrientes do solo identificados qualitativamente no campo e atributos de fertilidade do solo medidos em laboratório. Os resultados obtidos mostraram que os três primeiros componentes principais de todos os atributos da fertilidade explicaram $60 \%$ da variância total entre todas as parcelas consideradas. Carvalho Júnior et al. (2008) utilizaram a ACP e a análise discriminante na avaliação de atributos físicos e químicos de perfis de Argissolos, da faixa atlântica entre os Estados da Bahia e São Paulo, buscando aprofundar o conhecimento sobre as relações pedogeomorfológicas desses solos, com o intuito de permitir melhor separação das diferentes pedopaisagens. Os autores concluíram que as análises realizadas ampliaram o entendimento das relações geomorfopedológicas dos Argissolos dos diferentes domínios geomorfológicos estudados: os Argissolos dos Planaltos Soerguidos são mais rasos e de maior fertilidade natural que os Argissolos dos Tabuleiros Costeiros.

Este trabalho teve como objetivo aplicar a análise dos componentes principais para verificar as similaridades (agrupamentos) ou diferenças de amostras de solos de uma área, com base na granulometria e em seus atributos químicos e mineralógicos, e estabelecer relações com o material de origem, profundidade do solo e interferências antrópicas decorrentes de atividades de mineração e metalurgia de metais pesados.

\section{MATERIAL E MÉTODOS \\ Características gerais da área e amostragem dos solos \\ O estudo foi desenvolvido a partir de 8} perfis de solos, próximos ao Rio Ribeira, em área desativada de mineração e metalurgia de metais pesados, no município de Adrianópolis, PR. O clima da região é subtropical úmido mesotérmico, com verões quentes e tendência de concentração das chuvas (temperatura média superior a $22^{\circ} \mathrm{C}$ ) e invernos com geadas pouco freqüentes (temperatura média inferior a $18{ }^{\circ} \mathrm{C}$ ), sem estação de seca definida (Ipardes-PR, 2005).

A quadrícula de Adrianópolis apresenta geologia complexa, com as seguintes formações e litologias em ordem decrescente de ocorrência (Oliveira et al., 2002): 1) complexos granitóides (Três Córregos e Cunhaporanga); 2) dolomitos e carbonatos com baixo grau metamórfico; 3) rochas vulcano-sedimentar, com domínio de rochas psamo -pelíticas; 4) carbonatos e rochas psamo-pelíticas; 5) gnaisses variados, xistos e quartzitos de baixo a médio grau metamórfico e; 6) metabrechas, metaconglomerados e metapelitos.

A classificação da maioria dos solos como Neossolos Litólicos e Cambissolos (Tabela 1) refletiu a grande declividade da área (Figura 1). De acordo com Ureniuk (1992) a bacia do rio Ribeira apresenta relevo forte ondulado/montanhoso, com declividades acima de $15 \%$ e encostas com amplitudes locais de 100 a 300 m (relevos de morros isolados) ou superiores a $300 \mathrm{~m}$ (relevo montanhoso). A diferença de cota entre os pontos 1 e 8 (Figura 1) foi de $389 \mathrm{~m}$ (Tabela 1). 
KUMMER, L. et al. Uso da análise de componentes principais...

TABELA 1 - Localização, classificação dos solos e características dos locais de amostragem identificadas a campo, em Adrianópolis (PR).

\begin{tabular}{|c|c|c|c|c|c|}
\hline \multirow[b]{3}{*}{ Solo } & \multicolumn{2}{|c|}{ UTM (22J) } & \multirow[b]{3}{*}{ Altitude } & \multirow{3}{*}{$\begin{array}{c}\text { Classe } \\
\text { de Solo }\end{array}$} & \multirow{3}{*}{ Observações } \\
\hline & $\mathrm{N}-\mathrm{S}(\mathrm{m})$ & $\mathrm{E}-\mathrm{W}(\mathrm{m})$ & & & \\
\hline & Latitude & Longitude & & & \\
\hline 1 & $\begin{array}{c}7267313 \\
\text { S }\end{array}$ & $711502 \mathrm{~W}$ & $546 \mathrm{~m}$ & $\begin{array}{c}\text { Neossolo } \\
\text { Litólico }\end{array}$ & $\begin{array}{l}\text { Solo de referência sob mata nativa. Graças a } \\
\text { grande altitude do local em relação à fábrica } \\
\text { (diferença de cota de } 380 \mathrm{~m} \text { ), não havia } \\
\text { evidências da influência direta das atividades } \\
\text { de mineração no solo. Material de origem: } \\
\text { rochas carbonáticas/complexos granitóides. }\end{array}$ \\
\hline
\end{tabular}

$7268164 \quad 711513 \quad 326 \mathrm{~m}$

3

7268555

711287

$165 \mathrm{~m}$

Neossolo Litólico

4 7267907 711187 $327 \mathrm{~m}$

Mistura de sedimento mais rejeito fino ${ }^{(1)}$

5 $7268070 \quad 711360 \quad 316 m$ 7268671 711572 202 m

Mistura de solo mais rejeito grosseiro $^{(1)}$

7268671

(1)
Quartzarênico

$$
7
$$

7268499

711158

$194 \mathrm{~m}$

Cambissolo Háplico

8 7268701
$157 \mathrm{~m}$
Cambissolo
Posição intermediária da encosta, com evidência de deposição de colúvio vindo das partes mais altas. Material de origem: rochas carbonáticas/complexos granitóides.

Próximo à fábrica (Figura 1), com os horizontes do solo preservados e sem incorporação de rejeitos sólidos. Perfil na base da encosta. Material de origem: rochas carbonáticas/complexos granitóides.

Vale soterrado com pilhas de rejeitos, misturados ao solo. Como resultado, a camada de coleta de amostra $(0$ a $40 \mathrm{~cm})$ não apresentava estrutura e horizontes pedogenéticos. Material de origem: mistura de sedimentos argilosos mais rejeitos da metalurgia.

Grande ocorrência de rejeito na superfície incorporado ao solo. Como resultado, a camada de coleta de amostra (0 a $40 \mathrm{~cm}$ ) não apresentava estrutura e horizontes pedogenéticos. Material de origem: mistura de solo mais rejeitos da metalurgia.

Próximo à fábrica, com os horizontes do solo preservados e sem incorporação de rejeitos sólidos. Perfil na base da encosta. Material de origem: quartzito.

Terço inferior da encosta, com os horizontes do solo preservados e sem incorporação de rejeitos sólidos. Material de origem: rochas carbonáticas/complexos granitóides.

Neossolo Faixa entre a fábrica e o rio Ribeira e relevo Flúvico praticamente plano. Material de origem: sedimentos arenosos (fluviais).

\footnotetext{
(1) resíduo de mineração e metalurgia de chumbo intimar
pedogenéticos, não foi possível classificar os perfis de solos.

Os perfis foram localizados em diferentes ambientes de contaminação (solos 2 a 8) (Tabela 1), com o propósito de verificar o efeito da interferência antrópica no agrupamento dos solos por meio da análise por componentes principais (ACP). O solo 1 foi coletado a montante da área de mineração e metalurgia de $\mathrm{Pb}$ (380 m acima da cota da fábrica desativada) e com vegetação de mata nativa para representar os locais preservados da área. Foram coletadas amostras nas profundidades de $0-10,10-20$ e $20-40 \mathrm{~cm}$, que corresponderam
}

aos seguintes horizontes pedogenéticos (observar características dos perfis na Tabela 1): solos 1, 2, 3 e 7 - A1, A2 e A2; solos 4 e 5 - mistura de sedimento/solo mais rejeitos de mineração; solo 6 A, C1 e C2; solo 8 - A1, A2 e C1. Para se ter maior homogeneidade de horizontes e facilitar as comparações na $\mathrm{ACP}$, não foram tomadas amostras no horizonte $B$ dos Cambissolos (amostragem apenas mais superficial - até $40 \mathrm{~cm}$ ) pela ausência desse horizonte diagnóstico nos Neossolos. Outro fator determinante para coleta de 
KUMMER, L. et al. Uso da análise de componentes principais...

amostras de 0 a $40 \mathrm{~cm}$ é o maior efeito das atividades de mineração na superfície dos solos. As amostras foram secas ao ar e passados em peneira com malha de $2 \mathrm{~mm}$, para obtenção da terra fina seca ao ar (TFSA).

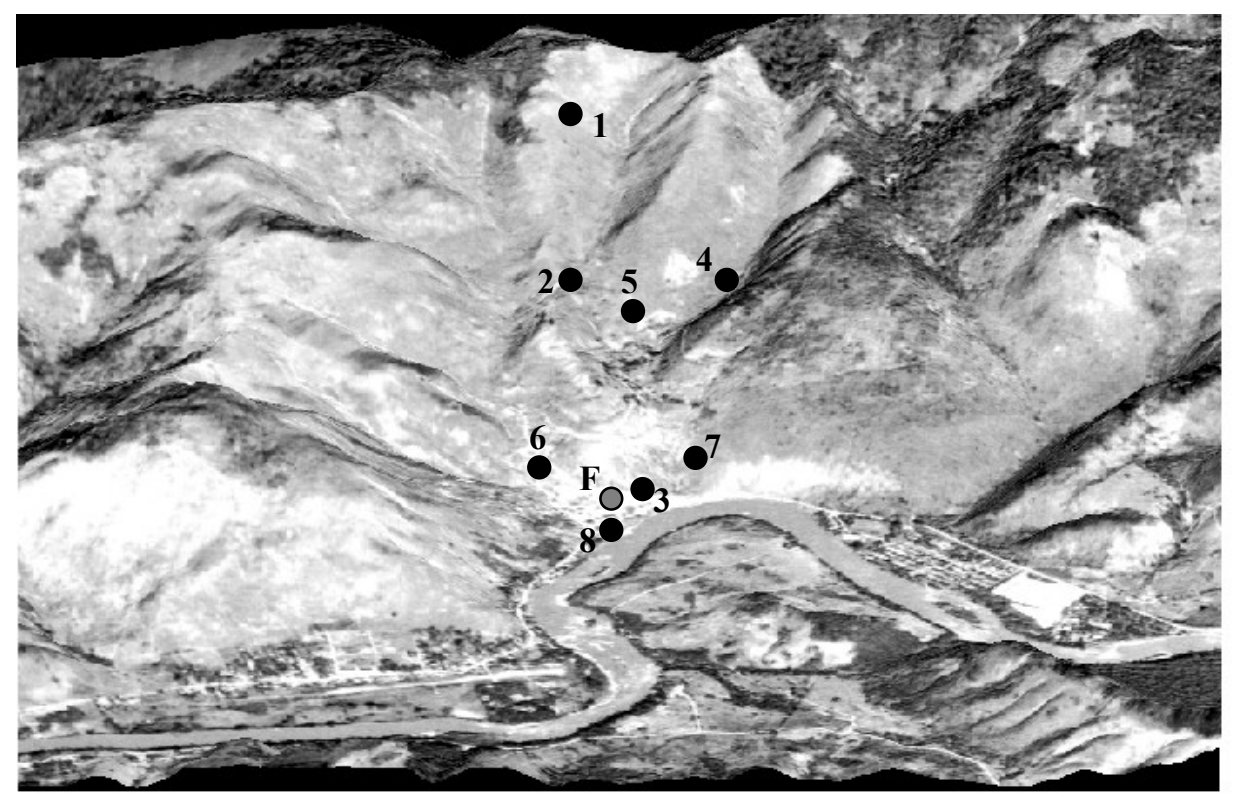

FIGURA 1 - Foto aérea com a localização da fábrica desativada (F) e os pontos de amostragem em Adrianópolis (PR) (1 a 8 - coordenadas geográficas apresentadas na Tabela 1).

\section{Análises químicas e granulométricas}

Para a caracterização química de rotina (fertilidade) das amostras de TFSA foram utilizados os métodos descritos em Embrapa (1997) e UFPR (2003): $\mathrm{pH}$ (em $\mathrm{H}_{2} \mathrm{O}$ ); carbono orgânico (dicromato de $\mathrm{Na}$ ); acidez potencial não-trocável $(\mathrm{H})$ (Acetato de $\left.\mathrm{Ca} 0,5 \mathrm{~mol} \mathrm{dm} \mathrm{pH}^{-3}, 0\right) ; \mathrm{Al}^{3+}, \mathrm{Ca}^{2+}, \mathrm{Mg}^{2+}$ e $\mathrm{Na}^{+}$ trocáveis $\left(\mathrm{KCl} 1 \mathrm{~mol} \mathrm{dm}^{-3}\right) ; \mathrm{K}^{+}$trocável (Mehlich 1 ). A análise textural foi conduzida pelo método da pipeta (Embrapa, 1997).

\section{Análises mineralógicas da fração argila}

As amostras foram tratadas com $\mathrm{H}_{2} \mathrm{O}_{2}$ a $30 \%$ para remoção de matéria orgânica, e com $\mathrm{NaOH} 0,2 \mathrm{~mol} \mathrm{dm}^{-3}$ para dispersão das partículas por agitação em agitador tipo orbital a $150 \mathrm{rpm}$. Após esses tratamentos prévios, a fração areia foi retida em peneira de $0,05 \mathrm{~mm}$ e as frações argila e silte foram recolhidas em provetas de $1.000 \mathrm{~cm}^{3} \mathrm{e}$ separadas por sedimentação com base na lei de Stokes (Melo et al., 2001a).

As amostras de argila foram moídas em almofariz e montadas em placas perfuradas (amostras não orientadas) para a identificação dos minerais por difratometria de raios $X(D R X)$. Os difratogramas foram obtidos em goniômetro vertical Philips, modelo PW1050/70, com velocidade de 1 ${ }^{\circ} 2 \theta \mathrm{min}^{-1}$ e amplitude de 4 a $65^{\circ} 2 \theta$. O difratômetro, equipado com filtro de $\mathrm{Ni}$ e utilizando radiação CuK $\alpha$, foi operado a $20 \mathrm{~mA}$ e $40 \mathrm{kV}$. Foram realizados tratamentos adicionais para diferenciar os minerais secundários do tipo 2:1 da fração de argila (Ghidin et al., 2006): saturação com Mg, saturação com Mg e solvatação com glicerol e saturação com $\mathrm{K}$ e secagem ao ar. Após os tratamentos, as amostras foram montadas em lâminas de vidro, utilizando-se a técnica do esfregaço (amostras orientadas), e analisadas por DRX, numa amplitude de 3 a $15^{\circ} 2 \theta$. Aproveitou-se a amostra saturada com K, e, após aquecimento a $550{ }^{\circ} \mathrm{C}$ em mufla, analisou-se novamente a lâmina por DRX nas mesmas condições.

Os óxidos de $\mathrm{Fe}$ da fração argila foram concentrados utilizando-se $\mathrm{NaOH} 5 \mathrm{~mol} \mathrm{dm}^{-3}$ a quente (Norrish \& Taylor, 1961). Foi adicionado silício, na forma de metassilicato de sódio $\left(\mathrm{Na}_{2} \mathrm{SiO}_{3} \cdot 5 \mathrm{H}_{2} \mathrm{O}\right)$, de modo que a concentração de $\mathrm{Si}$ na solução fosse de $0,2 \mathrm{~mol} \mathrm{dm}^{-3}$, evitando, assim, a dissolução de óxidos de ferro com alta substituição isomórfica em Al (Kämpf \& Schwertmann, 1982). A sodalita $\left[\mathrm{Na}_{4} \mathrm{Al}_{3} \mathrm{Si}_{3} \mathrm{O}_{12}(\mathrm{OH})\right]$ formada durante o tratamento com $\mathrm{NaOH} 5 \mathrm{~mol}$ $\mathrm{dm}^{-3}$ foi removida por lavagens com $\mathrm{HCl} 0,5 \mathrm{~mol}$ $\mathrm{dm}^{-3}$ (Norrish \& Taylor, 1961), empregando-se duas lavagens de $10 \mathrm{~min}$ com $50 \mathrm{~cm}^{3}$ de solução, sendo a suspensão continuamente agitada com bastão de 
KUMMER, L. et al. Uso da análise de componentes principais...

vidro (Singh \& Gilkes, 1991). A fração de óxidos de Fe concentrada foi analisada por DRX. A lâmina montada em pó foi analisada numa amplitude de 10 a $40^{\circ} 2 \theta$. Utilizou-se $\mathrm{NaCl}$ como padrão interno para correção das distorções instrumentais (posição e largura a meia altura dos picos). A mistura (em torno de $50 \mathrm{mg} \mathrm{g}^{-1}$ ) foi feita triturando-se a amostra em almofariz na presença de $\mathrm{NaCl}$. Para facilitar a medição da posição e da largura a meia altura dos picos, os difratogramas foram obtidos numa velocidade angular lenta do goniômetro $\left(0,1{ }^{\circ} 2 \theta\right.$ $\left.\min ^{-1}\right)$.

Para determinar os teores e a composição química dos óxidos de $\mathrm{Fe}$ de baixa cristalinidade e óxidos de $\mathrm{Fe}$ mais cristalinos, foram utilizadas extrações com oxalato de amônio $0,2 \mathrm{~mol} \mathrm{dm}^{-3}, \mathrm{pH}$ 3,0 (OA) (McKeague, 1978) e ditionito-citratobicarbonato (DCB) (Mehra \& Jackson, 1960), respectivamente, conforme detalhes apresentados por Melo et al. (2001a). Os teores de Fe foram determinados por espectrometria de absorção atômica (EAA). Após a lavagem do resíduo das extrações com OA e DCB com solução de $\left(\mathrm{NH}_{4}\right)$ ${ }_{2} \mathrm{CO}_{3} 1 \mathrm{~mol} \mathrm{dm}^{-3}$ e água deionizada para remover o excesso de sais, foi determinada a quantidade de material extraído pela diferença entre a massa seca (24 h em estufa a $60{ }^{\circ} \mathrm{C}$ ) antes e após os tratamentos.

A relação $(R)$ entre goethita $(G t)$ e hematita $(\mathrm{Hm})(\mathrm{R}=\mathrm{Gt} / \mathrm{Gt}+\mathrm{Hm})$ foi estimada com base na área dos picos dos minerais por DRX, segundo Torrent \& Cabedo (1986), em amostra previamente tratada com $\mathrm{NaOH} 5 \mathrm{~mol} \mathrm{dm}^{-3}$ (fração óxido de $\mathrm{Fe}$ concentrada). A substituição isomórfica (SI) de $\mathrm{Fe}$ por Al na estrutura da $\mathrm{Hm}$ e Gt foi estimada pela posição dos picos destes minerais, usando $\mathrm{NaCl}$ como padrão interno (Melo et al., 2001a): na Gt foi calculada segundo Schulze (1984) e na Hm segundo Schwertmann et al., (1979).

Os teores de $\mathrm{Hm}$ e $\mathrm{Gt}$ da fração argila foram estimados alocando-se os teores de $\mathrm{Fe}_{2} \mathrm{O}_{3}$ DCB de cada amostra, considerando-se a relação $\mathrm{Gt} /(\mathrm{Gt}+\mathrm{Hm})$, fórmula mínima desses minerais e substituição isomórfica de Fe por Al (Melo et al., 2001a).

As amostras da fração de argila, tratadas com DCB, foram analisadas em derivatógrafo SHIMADZU DTG-60, utilizando-se atmosfera de nitrogênio e taxa de aquecimento de $10{ }^{\circ} \mathrm{C} \mathrm{min}^{-1}$. A interpretação qualitativa foi feita pelas características dos picos endotérmico e exotérmico dos minerais em análise termodiferencial e a quantificação da caulinita (Ct) e gibbsita (Gb) foi realizada de acordo com a magnitude de redução da massa da amostra, em decorrência da desidroxilação dos minerais (Melo et al., 2001b). Para transformação dos teores de $\mathrm{Gb}$ e $\mathrm{Ct}$ da fração argila desferrificada para a fração argila natural, levou-se em conta a perda de massa da amostra com o tratamento com DCB.

\section{Análise de componentes principais}

Os dados foram submetidos à análise por componentes principais (ACP), com o objetivo de verificar quais os parâmetros químicos e mineralógicos poderiam ser utilizados para diferenciar ou para indicar similaridades entre as amostras de solos coletadas em diferentes locais (efeito do material de origem e interferência antrópica) e profundidades. O conjunto de métodos analíticos, cujos resultados configuram-se em uma matriz multidimensional, foi submetido à análise de $A C P$, que consiste de um conjunto de ferramentas estatísticas orientadas a comprimir a matriz original, sem perda de informação relevante (Geladi et al., 1989). Para a apresentação dos resultados optouse pelo ordenamento das amostras ("Scores") e das variáveis ("Loadings") no mesmo gráfico da ACP, ou seja, adotou-se a utilização de vetores identificando os principais fatores (variáveis) responsáveis pelos agrupamentos das amostras.

\section{RESULTADOS E DISCUSSÃO}

\section{Análise textural e química}

Os solos 4, 5, 6 e 8 apresentaram textura variando de média a arenosa (Tabela 2 ). 0 solo 5 , por conter grande quantidade de rejeitos de siderurgia sobre a superfície, apresentou no horizonte A1 o predomínio de fração areia. A ocorrência de rejeitos no solo 4 também reduziu o seu teor de argila. Já no caso dos solos 6 e 8 o maior teor de areia foi atribuído ao material de origem: quartzito e deposição de sedimentos provenientes do rio, respectivamente (Tabela 1). Os demais solos, originados de rochas carbonáticas/ complexos granitóides e sem a incorporação de rejeitos de mineração, apresentaram textura argilosa.

Com exceção do solo 6 (quartzito), os teores de $\mathrm{Ca}^{2+}$ foram elevados (Tabela 2), resultados compatíveis com a ocorrência de rochas carbonáticas na região. Esse solo foi o único a ter valores de $\mathrm{pH}$ inferiores a 6,5 (variação de 4,6 a $4,9)$ e possuir acidez potencial trocável $\left(\mathrm{Al}^{3+}\right.$ maior que $1 \mathrm{cmol}_{\mathrm{c}} \mathrm{dm}^{-3}$ ).

Os menores teores de carbono orgânico (CO) foram encontrados nas camadas de 10-20 e de 20-40 cm nos solos 4 e 6 em conseqüência da mistura de rejeitos e dos menores teores de argila, respectivamente. A combinação de baixos teores de $\mathrm{CO}$ e de argila determinou reduzidos valores de CTC nas amostras do solo 6 (Tabela 2). A baixa CTC da amostra $5(0-10 \mathrm{~cm})$ é justificada pela grande diluição dos componentes coloidais com a intensa mistura de rejeitos grosseiros da siderurgia.

Os resultados das análises químicas e os teores de argila e areia, referentes aos oito solos e as três diferentes profundidades, foram ordenados através da ACP (Figura 2), onde os componentes principais 1 e 2 (PCA-1 e PCA-2) explicaram 84,6\%, sendo que a PCA-1 explicou $71,5 \%$ e a PCA-2 $13,2 \%$ da variabilidade total dos dados. Os escores do componente principal 1 correlacionaram-se positivamente com o Ca ${ }^{2+}(r=0,99)$, CTC $(r=0,98)$, $\mathrm{pH}(r=0,70)$, e argila $(r=0,82)$; negativamente, com os teores de areia $(r=-0,81)$ e $\mathrm{Al}^{3+}(r=0,93)$. A componente principal 2 correlacionou-se negativamente com o $\mathrm{pH}(r=-0,70)$. 
KUMMER, L. et al. Uso da análise de componentes principais...

TABELA 2 - Análise granulométrica e atributos químicos das amostras de solos de Adrianópolis (PR).

\begin{tabular}{|c|c|c|c|c|c|c|c|c|c|c|c|c|c|c|c|}
\hline \multirow{2}{*}{$\begin{array}{l}\text { Solo/ } \\
\text { Prof. }(\mathrm{cm}) / \\
\text { Horizonte }\end{array}$} & \multirow{2}{*}{$\begin{array}{c}\mathrm{pH} \\
\mathrm{H}_{2} \mathrm{O}\end{array}$} & $\mathrm{Al}^{3+}$ & $\begin{array}{l}\mathrm{H}+ \\
\mathrm{Al}^{3+}\end{array}$ & $\mathrm{Ca}^{2+}$ & $\mathrm{Mg}^{2}$ & $\mathrm{~K}^{+}$ & $\mathrm{Na}^{+}$ & $\underset{(2)}{\mathrm{SB}}$ & $\underset{(2)}{\text { CTC }}$ & $\begin{array}{l}\mathrm{T} \\
(2)\end{array}$ & $\mathrm{C}_{(2)} \mathrm{O}$. & $\mathrm{V}^{(2)}$ & Areia & Silte & Argila \\
\hline & & - & & & & $-\mathrm{cmol}_{\mathrm{C}}$ & $\mathrm{dm}^{-3}-$ & & & ---- & $g d m$ & $\%$ & \multicolumn{2}{|c|}{-----------g kg } & -1------ \\
\hline $1(0-10)(A 1)$ & 6,7 & 0,0 & 4,5 & 23,7 & 3,2 & 0,19 & 0,09 & 27,2 & 31,7 & 66,5 & 45,0 & 86 & 162 & 362 & 477 \\
\hline $1(10-20)(\mathrm{A} 2)$ & 6,4 & 0,0 & 6,3 & 19,4 & 3,4 & 0,10 & 0,08 & 23,0 & 29,3 & 57,8 & 29,3 & 79 & 169 & 324 & 507 \\
\hline $1(20-40)(A 2)$ & 6,8 & 0,0 & 4,0 & 24,2 & 2,8 & 0,09 & 0,08 & 27,2 & 31,2 & 60,4 & 26,9 & 87 & 170 & 314 & 516 \\
\hline $2(0-10)(A 1)$ & 6,6 & 0,0 & 4,6 & 26,4 & 3,5 & 0,13 & 0,06 & 30,1 & 34,7 & 78,7 & 37,7 & 87 & 98 & 461 & 441 \\
\hline $2(10-20)(\mathrm{A} 2)$ & 7,3 & 0,0 & 1,3 & 30,4 & 2,5 & 0,11 & 0,07 & 33,0 & 34,4 & 75,9 & 28,1 & 96 & 106 & 442 & 453 \\
\hline $2(20-40)(\mathrm{A} 2)$ & 7,7 & 0,0 & 0,2 & 26,8 & 3,4 & 0,07 & 0,07 & 30,3 & 30,5 & 69,3 & 19,0 & 100 & 89 & 471 & 440 \\
\hline $3(0-10)(A 1)$ & 6,9 & 0,0 & 1,3 & 25,5 & 1,8 & 0,48 & 0,09 & 27,8 & 29,2 & 67,3 & 45,6 & 96 & 204 & 363 & 434 \\
\hline $3(10-20)(\mathrm{A} 2)$ & 6,8 & 0,0 & 0,8 & 25,5 & 2,3 & 0,44 & 0,08 & 28,3 & 29,1 & 62,8 & 37,7 & 97 & 204 & 332 & 464 \\
\hline $3(20-40)(\mathrm{A} 2)$ & 6,8 & 0,0 & 1,3 & 25,5 & 1,7 & 0,30 & 0,08 & 27,6 & 28,9 & 68,2 & 37,7 & 95 & 188 & 388 & 424 \\
\hline $4(0-10)^{(1)}$ & 8,4 & 0,0 & 0,0 & 23,8 & 1,2 & 0,47 & 0,10 & 25,5 & 25,5 & 96,1 & 26,3 & 100 & 179 & 556 & 266 \\
\hline $4(10-20)$ & 8,3 & 0,0 & 0,0 & 32,5 & 2,6 & 0,26 & 0,09 & 35,5 & 35,5 & 167,3 & 6,3 & 100 & 120 & 668 & 212 \\
\hline $4(20-40)$ & 8,4 & 0,0 & 0,0 & 28,9 & 2,0 & 0,25 & 0,20 & 31,3 & 31,3 & 123,1 & 6,3 & 100 & 99 & 646 & 255 \\
\hline $5(0-10)^{(1)}$ & 8,3 & 0,0 & 0,0 & 10,1 & 0,5 & 0,45 & 0,28 & 11,3 & 11,3 & 235,0 & 28,1 & 100 & 807 & 145 & 48 \\
\hline $5(10-20)$ & 8,3 & 0,0 & 0,0 & 24,3 & 1,5 & 0,33 & 0,20 & 26,4 & 26,4 & 75,6 & 20,8 & 100 & 336 & 315 & 349 \\
\hline $5(20-40)$ & 8,0 & 0,0 & 0,0 & 27,8 & 2,3 & 0,19 & 0,20 & 30,5 & 30,5 & 97,3 & 13,0 & 100 & 184 & 503 & 313 \\
\hline $6(0-10)(A)$ & 4,9 & 1,0 & 4,9 & 1,8 & 0,5 & 0,24 & 0,06 & 2,6 & 7,5 & 60,9 & 11,8 & 34 & 730 & 147 & 124 \\
\hline $6(10-20)(C 1)$ & 4,6 & 1,3 & 4,1 & 0,0 & 0,0 & 0,12 & 0,04 & 0,2 & 4,3 & 45,3 & 6,9 & 4 & 747 & 158 & 95 \\
\hline $6(20-40)(C 2)$ & 4,6 & 1,2 & 3,0 & 0,4 & 0,0 & 0,11 & 0,04 & 0,5 & 3,5 & 54,5 & 6,3 & 15 & 777 & 159 & 64 \\
\hline $7(0-10)(\mathrm{A} 1)$ & 8,3 & 0,0 & 0,0 & 24,9 & 1,4 & 0,68 & 0,15 & 27,1 & 27,1 & 56,1 & 30,5 & 100 & 151 & 365 & 483 \\
\hline $7(10-20)(A 2)$ & 8,3 & 0,0 & 0,0 & 28,1 & 0,7 & 0,60 & 0,11 & 29,5 & 29,5 & 57,4 & 18,4 & 100 & 125 & 361 & 515 \\
\hline $7(20-40)(\mathrm{A} 2)$ & 8,2 & 0,0 & 0,0 & 29,2 & 1,0 & 0,50 & 0,09 & 30,7 & 30,7 & 55,9 & 17,8 & 100 & 117 & 334 & 549 \\
\hline $8(0-10)(A 1)$ & 8,3 & 0,0 & 0,0 & 12,2 & 0,6 & 0,30 & 0,19 & 13,3 & 13,3 & 89,2 & 20,8 & 100 & 586 & 265 & 149 \\
\hline $8(10-20)(A 2)$ & 8,3 & 0,0 & 0,0 & 12,4 & 1,2 & 0,22 & 0,20 & 14,0 & 14,0 & 67,9 & 19,8 & 100 & 553 & 241 & 206 \\
\hline $8(20-40)(C 1)$ & 8,2 & 0,0 & 0,0 & 19,5 & 2,0 & 0,23 & 0,16 & 21,9 & 21,9 & 69,0 & 17,8 & 100 & 353 & 329 & 318 \\
\hline
\end{tabular}


KUMMER, L. et al. Uso da análise de componentes principais...

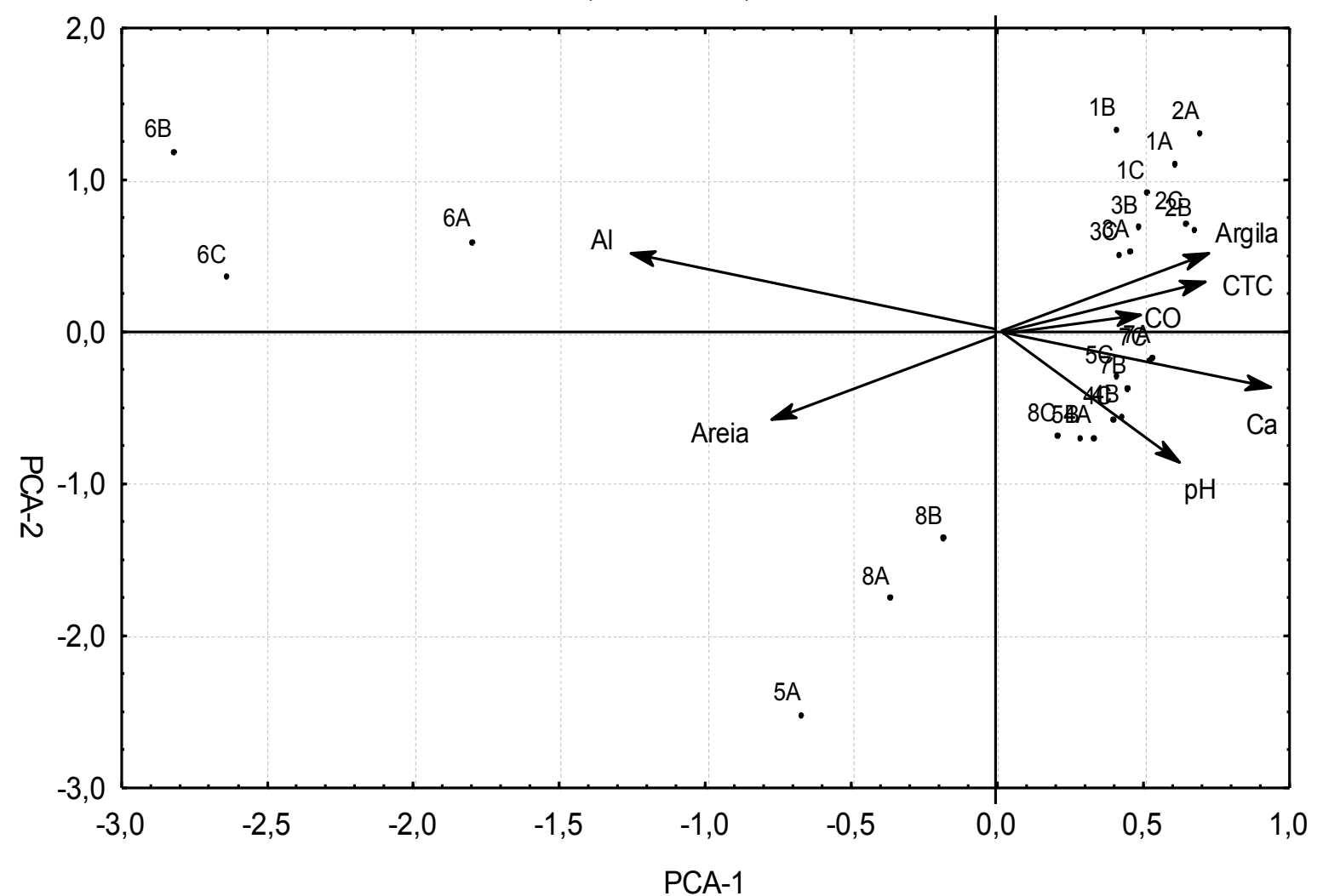

FIGURA 2 - Componentes principais (PCA-1 e PCA-2) dos resultados químicos e teores de argila e areia de amostras de solos de Adrianópolis (PR): os pontos representam o ordenamento das amostras [solos (1 a 8) e profundidade (A $-0-10 \mathrm{~cm}, \mathrm{~B}-10-20 \mathrm{~cm}, \mathrm{C}-20-40 \mathrm{~cm}$ )] e as setas o ordenamento das variáveis.

A ACP demonstrou que o agrupamento ocorreu mais em função do local de coleta, do que das profundidades de amostragem (camadas e horizontes). As amostras dos horizontes do solo 6 (A, C1 e C2) e do solo 8 (A1 e A2) e da camada 0 $10 \mathrm{~cm}$ do solo 5 foram agrupadas no lado esquerdo da ACP (Figura 2), em função da textura mais grosseira; a separação do solo 6 no eixo superior deveu-se a presença de $\mathrm{Al}^{3+}$ apenas nesse solo (Tabela 2). Com isso, com base no material de origem, os solos foram divididos em dois ambientes: arenosos e argilosos, sendo que os últimos apresentaram maiores teores de $\mathrm{Ca}^{2+}$ e valores de CTC (vetores direcionados para o lado esquerdo do gráfico). Contudo, o efeito do material de origem foi anulado pela atividade antrópica na camada mais superficial do solo 5 (incorporação de rejeitos de siderurgia do tamanho areia), que possui o mesmo material de origem dos solos 1, 2, 3 e 7 (rochas carbonáticas/complexos granitóides). A textura mais fina da amostra 8C (solo 8, horizonte C1), característica responsável por sua dispersão para o lado direito do gráfico, provavelmente, foi decorrente da deposição de sedimentos mais argilosos no horizonte $\mathrm{C} 1$ pelo rio; esses sedimentos determinaram maiores valores de CTC e teores de $\mathrm{Ca}^{2+}$ em relação aos horizontes superiores. Em Neossolos Flúvicos, devido à maior heterogeneidade do material de origem, tem-se efeito expressivo do horizonte amostrado (Lages, 2005; Embrapa, 2006). Além disso, a separação entre o eixo superior e inferior foi fortemente influenciada pelos valores de $\mathrm{pH}$ : eixo superior $\mathrm{pH}$ menor que 7,0 e inferior maior que 8,0.

O grupo formado no quadrante superior direito pelas amostras dos solos 1,2 e 3 (delimitados por uma elipse na figura 2) refletiu os maiores teores de $\mathrm{CO}$, além das maiores quantidades de argila e teores de $\mathrm{Ca}^{2+}$. Esses três solos foram formados de rochas carbonáticas/ complexos granitóides, o que reforça a importância do material de origem nas características químicas e texturais dos solos. A presença de colúvio no solo 2, favorecida por sua posição de meia encosta (Tabela 1 e Figura 1), não ocasionou sua diferenciação em relação aos solos 1 e 3 (autóctones) na ACP; a fonte dos sedimentos a montante do ponto 2 também foi o intemperismo das mesmas rochas (carbonáticas/complexos granitóides). Não houve dispersão das amostras desses solos tomadas em diferentes horizontes no gráfico da $\mathrm{ACP}$, evidenciando a homogeneidade dos perfis até $40 \mathrm{~cm}$.

As amostras do solo 7 ficaram na porção inferior do gráfico da ACP (Figura 2). Mesmo próximo geograficamente ao solo 3 (parte mais 
KUMMER, L. et al. Uso da análise de componentes principais...

baixa da área - Figura 1), possivelmente, a formação do solo 7 foi mais influenciada por rochas carbonáticas, o que elevou seus valores de $\mathrm{pH}$ acima de 8,0 nos horizontes A1 e A2 (Tabela 2).

As amostras do solo 4 formaram um grupo bastante homogêneo no quadrante inferior direito (Figura 2) devido ao pH básico $(8,3$ - 8,4) e aos menores teores de $\mathrm{CO}$. O rejeito fino misturado ao solo 4 foi proveniente do processo de metalurgia do $\mathrm{Pb}$, o que, provavelmente, levou à formação de óxidos ( $\mathrm{CaO}$ e $\mathrm{MgO}$ ) com alta capacidade corretiva. Já as amostras do ponto 5 ficaram mais dispersas em função das diferentes quantidades de rejeitos grosseiros incorporados em cada profundidade: amostra $0-10 \mathrm{~cm}$ no quadrante esquerdo $\mathrm{e}$ amostras $10-20 \mathrm{~cm}$ e $20-40 \mathrm{~cm}$ no direito em conseqüência da menor participação dos resíduos na fração areia e dos maiores teores de $\mathrm{Ca}^{2+}$. Dessa forma, a interferência antrópica decorrente da mineração definiu características diferenciadas das camadas e, por consequência, a dispersão das amostras do solo 5 .

O posicionamento de todas as amostras do solo 8 no eixo inferior do gráfico da ACP deveu-se, principalmente, aos elevados valores de $\mathrm{pH}(8,2$ $8,3)$.

\section{Análise mineralógica}

Os teores de óxidos de Fe extraídos com oxalato de amônio (OA) e com ditionito-citratobicarbonato (DCB) (Tabela 3) foram baixos, o que está relacionado à pobreza dos materiais de origem da região em minerais primários ferromagnesianos. Os teores de $\mathrm{Fe}_{2} \mathrm{O}_{3}$-DCB da fração argila de solos originados de rochas básicas, por exemplo, ultrapassam $250 \mathrm{~g} \mathrm{~kg}^{-1}$ (Melo et al., 2001a; Ghidin et al., 2006).

TABELA 3 - Teores de óxidos de ferro de baixa (extração com oxalato de amônio - OA) e alta cristalinidade (extração com ditionito-citrato-bicarbonato - DCB) e relação goethita/(goethita+hematita) $[\mathrm{Gt} /(\mathrm{Gt}+\mathrm{Hm})]$ nas amostras da fração argila de solos de Adrianópolis (PR)

\begin{tabular}{|c|c|c|c|c|c|}
\hline \multirow{2}{*}{$\begin{array}{c}\text { Solo/ } \\
\text { Prof. }(\mathrm{cm}) / \\
\text { Horizonte }\end{array}$} & $\begin{array}{c}\text { Oxalato } \\
(\mathrm{OA})\end{array}$ & $\begin{array}{c}\begin{array}{c}\text { Ditionito } \\
\text { (DCB) }\end{array} \\
\end{array}$ & \multirow[b]{2}{*}{$\begin{array}{l}\mathrm{Fe}_{2} \mathrm{O}_{3} \text { Total } \\
(\mathrm{AO}+\mathrm{DCB})\end{array}$} & \multirow{2}{*}{$\begin{array}{c}\text { Relação } \\
\text { FeOA/FeDCB }\end{array}$} & \multirow{2}{*}{$\begin{array}{c}\mathrm{Gt} / \\
(\mathrm{Gt}+\mathrm{Hm})\end{array}$} \\
\hline & $\mathrm{Fe}_{2} \mathrm{O}_{3}$ & $\begin{array}{r}\mathrm{Fe}_{2} \mathrm{O}_{3} \\
---\mathrm{g} \mathrm{kg}^{-1} \\
\end{array}$ & & & \\
\hline $1(0-10)(\mathrm{A} 1)$ & 12,4 & 24,3 & 36,7 & 0,51 & 0,29 \\
\hline $1(10-20)(A 2)$ & 10,2 & 31,2 & 41,4 & 0,33 & 0,19 \\
\hline $1(20-40)(\mathrm{A} 2)$ & 19,1 & 20,1 & 39,2 & 0,95 & 0,18 \\
\hline $2(0-10)(\mathrm{A} 1)$ & 2,4 & 26,9 & 29,2 & 0,09 & 0,69 \\
\hline $2(10-20)(\mathrm{A} 2)$ & 1,6 & 39,7 & 41,3 & 0,04 & 0,61 \\
\hline $2(20-40)(\mathrm{A} 2)$ & 2,9 & 37,6 & 40,5 & 0,08 & 0,75 \\
\hline $3(0-10)(A 1)$ & 10,4 & 24,5 & 34,9 & 0,42 & 0,46 \\
\hline $3(10-20)(\mathrm{A} 2)$ & 5,3 & 36,0 & 41,3 & 0,15 & 0,43 \\
\hline $3(20-40)(\mathrm{A} 2)$ & 5,7 & 35,3 & 41,0 & 0,16 & 0,46 \\
\hline $4(0-10)^{(1)}$ & 10,4 & 33,0 & 43,5 & 0,32 & 1,00 \\
\hline $4(10-20)$ & 8,2 & 20,8 & 29,0 & 0,39 & 1,00 \\
\hline $4(20-40)$ & 8,7 & 36,3 & 44,9 & 0,24 & 0,93 \\
\hline $5(0-10)^{(1)}$ & 1,0 & 36,9 & 37,9 & 0,03 & 0,92 \\
\hline $5(10-20)$ & 4,0 & 35,7 & 39,6 & 0,11 & 0,98 \\
\hline $5(20-40)$ & 11,8 & 27,4 & 39,2 & 0,43 & 0,85 \\
\hline $6(0-10)(A)$ & 10,3 & 34,3 & 44,5 & 0,30 & 1,00 \\
\hline $6(10-20)(C 1)$ & 10,2 & 24,0 & 34,2 & 0,43 & 1,00 \\
\hline $6(20-40)(C 2)$ & 10,3 & 33,1 & 43,4 & 0,31 & 1,00 \\
\hline $7(0-10)(A 1)$ & 8,4 & 35,9 & 44,4 & 0,24 & 0,54 \\
\hline $7(10-20)(\mathrm{A} 2)$ & 6,6 & 34,1 & 40,7 & 0,19 & 0,68 \\
\hline $7(20-40)(\mathrm{A} 2)$ & 7,4 & 31,6 & 38,9 & 0,23 & 0,72 \\
\hline $8(0-10)(\mathrm{A} 1)$ & 9,4 & 32,7 & 42,1 & 0,29 & 1,00 \\
\hline $8(10-20)(\mathrm{A} 2)$ & 9,7 & 36,9 & 46,6 & 0,26 & 1,00 \\
\hline $8(20-40)(C 1)$ & 9,9 & 35,9 & 45,8 & 0,27 & 0,82 \\
\hline
\end{tabular}

\footnotetext{
(1) Ausência de horizontes pedogenéticos - mistura de sedimento/solo e rejeitos da metalurgia de $\mathrm{Pb}$.
} 
KUMMER, L. et al. Uso da análise de componentes principais...

Mesmo com predomínio de óxidos de $\mathrm{Fe}$ mais cristalinos, os valores da relação $\mathrm{FeOA} /$ FeDCB foram relativamente altos, compatíveis com o menor grau de intemperismo dos solos (Neossolos e Cambissolos) e elevados teores de $\mathrm{CO}$ das amostras (Tabela 2). A fração húmica tem efeito inibidor na cristalização dos óxidos de $\mathrm{Fe}$ (Schwertmann, 1991; Ghidin et al., 2006). Em latossolos é comum encontrar valores para essa relação inferiores a 0,01 (Melo et al., 2001a).

De maneira geral, os valores da relação $[\mathrm{Gt} /(\mathrm{Gt}+\mathrm{Hm})]$ nos solos decresceram em profundidade (Tabela 3 ). Estes resultados podem ser creditados à maior quantidade de matéria orgânica na camada superficial, uma vez que esta favorece a formação da $\mathrm{Gt}$, por complexar o $\mathrm{Fe}$ retirando-o da solução do solo (Schwertmann, 1991).

Verificou-se a ocorrência de esmectita em todas as amostras, com exceção do ponto 6. Estima -se expressiva ocorrência desse mineral nos solos, dada a grande diferença entre a soma de minerais em relação ao conteúdo total de argila (Tabela 4), o que é coerente com o alto valor de atividade da fração argila ( $T$ ) das amostras (maior que $27 \mathrm{cmol}_{\mathrm{c}}$ $\mathrm{kg}^{-1}$ - Embrapa, 2006) (Tabela 2).

TABELA 4 - Composição mineralógica da fração argila das amostras de solos de Adrianópolis (PR) $)^{(1)}$

\begin{tabular}{|c|c|c|c|c|c|c|c|c|c|c|c|c|c|}
\hline \multirow{2}{*}{$\begin{array}{c}\text { Solo/ } \\
\text { Prof. }(\mathrm{cm}) / \\
\text { Horizonte }\end{array}$} & $\mathrm{Ct}$ & $\mathrm{Gb}$ & $\mathrm{Hm}$ & Gt & $\begin{array}{c}\text { Material } \\
\text { amorfo }\end{array}$ & Total & \multirow[t]{2}{*}{ Esmectita } & \multirow[t]{2}{*}{ EHE } & \multirow[t]{2}{*}{ Mica } & \multirow[t]{2}{*}{$\mathrm{Fd}$} & \multirow[t]{2}{*}{ Qz } & \multirow[t]{2}{*}{ Calcita } & \multirow[t]{2}{*}{ Talco } \\
\hline & \multicolumn{6}{|c|}{ - } & & & & & & & \\
\hline $1(0-10)(\mathrm{A} 1)$ & 537,4 & 35,9 & 19,7 & 7,8 & 55,6 & 656,4 & $\mathrm{nq}$ & $\mathrm{nq}$ & - & - & $\mathrm{nq}$ & - & nq \\
\hline 1(10-20) (A2) & 541,6 & 34,4 & 33,1 & 7,7 & 75,3 & 692,2 & $\mathrm{nq}$ & - & - & - & $\mathrm{nq}$ & - & nq \\
\hline $1(20-40)(\mathrm{A} 2)$ & 534,2 & 33,4 & 19,0 & 4,1 & 50,0 & 640,8 & $\mathrm{nq}$ & $\mathrm{nq}$ & - & - & nq & - & $\mathrm{nq}$ \\
\hline $2(0-10)(A 1)$ & 438,6 & 51,3 & 9,7 & 21,4 & 57,8 & 578,8 & $\mathrm{nq}$ & $\mathrm{nq}$ & - & - & $\mathrm{nq}$ & - & $\mathrm{nq}$ \\
\hline $2(10-20)(\mathrm{A} 2)$ & 423,3 & 50,0 & 19,4 & 30,4 & 54,6 & 577,8 & $\mathrm{nq}$ & $\mathrm{nq}$ & - & - & $\mathrm{nq}$ & - & $\mathrm{nq}$ \\
\hline $2(20-40)(A 2)$ & 441,6 & 40,0 & 10,6 & 31,8 & 44,6 & 568,6 & $\mathrm{nq}$ & $\mathrm{nq}$ & - & - & nq & - & $\mathrm{nq}$ \\
\hline $3(0-10)(A 1)$ & 534,4 & 43,7 & 14,1 & 11,8 & 54,1 & 658,1 & $\mathrm{nq}$ & - & - & $\mathrm{nq}$ & $\mathrm{nq}$ & - & - \\
\hline $3(10-20)(\mathrm{A} 2)$ & 535,5 & 36,2 & 23,0 & 17,1 & 42,6 & 654,4 & $\mathrm{nq}$ & - & - & $\mathrm{nq}$ & $\mathrm{nq}$ & - & - \\
\hline $3(20-40)(A 2)$ & 518,5 & 41,2 & 21,5 & 18,4 & 26,4 & 626,1 & $\mathrm{nq}$ & - & - & $\mathrm{nq}$ & $\mathrm{nq}$ & - & - \\
\hline $4(0-10)^{(2)}$ & 494,8 & 39,5 & 0,0 & 36,8 & 60,6 & 631,6 & $\mathrm{nq}$ & $\mathrm{nq}$ & $\mathrm{nq}$ & nq & $\mathrm{nq}$ & - & $\mathrm{nq}$ \\
\hline $4(10-20)$ & 441,3 & 29,3 & 0,1 & 27,6 & 86,2 & 584,4 & $\mathrm{nq}$ & - & - & nq & nq & - & $\mathrm{nq}$ \\
\hline $4(20-40)$ & 497,8 & 39,9 & 3,1 & 41,8 & 34,7 & 617,4 & $\mathrm{nq}$ & - & - & nq & nq & - & $\mathrm{nq}$ \\
\hline $5(0-10)^{(2)}$ & 443,4 & 35,1 & 3,2 & 37,9 & 96,9 & 616,4 & $\mathrm{nq}$ & - & - & - & $\mathrm{nq}$ & - & - \\
\hline $5(10-20)$ & 532,4 & 45,4 & 0,8 & 41,4 & 26,0 & 646,0 & $\mathrm{nq}$ & - & $\mathrm{nq}$ & - & nq & - & - \\
\hline $5(20-40)$ & 445,0 & 46,1 & 4,8 & 27,3 & 19,9 & 543,0 & $\mathrm{nq}$ & - & - & - & nq & $\mathrm{nq}$ & - \\
\hline $6(0-10)(A)$ & 525,6 & 21,2 & 0,0 & 41,1 & 58,4 & 646,3 & - & - & $\mathrm{nq}$ & nq & $\mathrm{nq}$ & $\mathrm{nq}$ & - \\
\hline $6(10-20)(C 1)$ & 505,8 & 16,2 & 0,0 & 27,4 & 102,4 & 651,8 & - & - & $\mathrm{nq}$ & nq & nq & $\mathrm{nq}$ & - \\
\hline $6(20-40)(C 2)$ & 494,0 & 24,4 & 0,0 & 41,2 & 75,2 & 634,8 & - & - & $\mathrm{nq}$ & $\mathrm{nq}$ & nq & - & - \\
\hline $7(0-10)(A 1)$ & 595,2 & 34,8 & 19,2 & 22,2 & 69,4 & 740,9 & $\mathrm{nq}$ & - & - & nq & $\mathrm{nq}$ & - & - \\
\hline 7 (10-20) (A2) & 601,8 & 32,7 & 13,6 & 28,6 & 61,7 & 738,4 & $\mathrm{nq}$ & - & - & nq & nq & - & - \\
\hline 7 (20-40) (A2) & 674,5 & 45,5 & 10,5 & 26,9 & 61,1 & 818,6 & $\mathrm{nq}$ & - & - & nq & $\mathrm{nq}$ & - & $\mathrm{nq}$ \\
\hline $8(0-10)(A 1)$ & 501,8 & 32,2 & 0,0 & 38,5 & 71,9 & 644,4 & $\mathrm{nq}$ & $\mathrm{nq}$ & $\mathrm{nq}$ & $\mathrm{nq}$ & nq & - & - \\
\hline $8(10-20)(A 2)$ & 509,1 & 40,2 & 0,0 & 45,4 & 91,1 & 685,8 & $\mathrm{nq}$ & $\mathrm{nq}$ & - & $\mathrm{nq}$ & nq & - & $\mathrm{nq}$ \\
\hline $8(20-40)(C 1)$ & 538,3 & 21,5 & 7,6 & 35,1 & 79,8 & 682,2 & $\mathrm{nq}$ & $\mathrm{nq}$ & - & $\mathrm{nq}$ & $\mathrm{nq}$ & - & - \\
\hline
\end{tabular}


KUMMER, L. et al. Uso da análise de componentes principais...

Praticamente metade da fração argila é composta por Ct (Tabela 4). Tal fato é devido ao clima tropical úmido da região, o que favorece a remoção de Si e formação de mineral $1: 1$, mesmo em solos jovens associados a relevo acidentado. Diversos autores encontraram a Ct como o principal componente da fração argila de diferentes classes de solos tropicais e subtropicais (Melo et al., 2001b; Wowk \& Melo, 2005; Barros et al., 2008).

Os teores de $\mathrm{Gb}$, Gt e $\mathrm{Hm}$ foram muito baixos. A coexistência de altos teores de $\mathrm{Gb}$ e esmectita na fração argila não é favorecida, pois a formação do primeiro mineral é expressiva apenas em ambientes com remoção quase total de Si solúvel (concentrações próximas a zero na solução do solo) e solos com elevado grau de intemperismo (Latossolos) (Melo et al., 2001a).

Verificou-se a presença de quartzo na fração argila de todas as amostras, que mesmo sendo um mineral solúvel com tamanho menor que $0,002 \mathrm{~mm}$, também já foi observado em outros estudos (Melo et al., 2001a; Ghidin et al., 2006). A calcita na fração argila foi devido à litologia da região (materiais calcíticos e carbonáticos), em conjunto com mica, talco e feldspato advindos do substrato granítico (Oliveira et al., 2002).

Os resultados mineralógicos foram ordenados através de ACP, onde os componentes principais 1 e 2 (PCA-1 e PCA-2) explicaram 70,5\%, sendo que a PCA-1 explicou $42,1 \%$ e a PCA-2 $28,4 \%$ da variabilidade total dos dados (Figura 3 ). Os escores do componente principal 1 (PCA-1) correlacionaram-se positivamente com o teor de Gt $(r=0,70)$; negativamente, com a $\mathrm{Hm}(r=-0,88)$ e com a concentração de $\mathrm{Gb}(r=-0,70)$. A componente principal 2, correlacionou-se positivamente com a $\mathrm{Ct}(r=0,70)$.

O posicionamento das amostras nos quadrantes do gráfico da ACP (Figura 3) foi determinado, principalmente, pelas seguintes variáveis (teores de minerais): direita - Gt; esquerda - $\mathrm{Hm}$; inferior - $\mathrm{Gb}$. Observou-se correlação negativa entre os teores de $\mathrm{Hm}$ e $\mathrm{Gt}$ nas amostras $(r=-0,81, p<0,001)$. As amostras com mais $\mathrm{Hm}$ e menos $\mathrm{Gt}$ deslocaram-se para a esquerda (Figura 3). Esses solos também apresentaram os maiores teores de Ct (534 a $674 \mathrm{~g}$ $\mathrm{kg}^{-1}$ ), o que resultou na formação de três grupos homogêneos no quadrante superior esquerdo (amostras do solo 1; amostras do solo 7; horizontes A1 e A2 $(10-20 \mathrm{~cm})$ do solo 3$)$. Além disso, o que contribuiu para esses agrupamentos foram os menores teores de $\mathrm{Gb}$ nesses solos. Esse comportamento evidencia a homogeneidade mineralógicas dos diferentes sub horizontes do horizonte superficial dos solos e pequena dispersão mineralógica entre Neossolos (1 e 3) e Cambissolo (7) em relevo forte ondulado/montanhoso, quando se compara o mesmo horizonte pedogenético (horizonte A).

Os menores teores de Ct e material amorfo induziram o afastamento da amostra $3 \mathrm{C}$ do grupo de amostras do solo 3 . Em relação às características químicas (Figura 2), houve dispersão das amostras do solo 2, afastando-se do quadrante dos solos 1 e 3 (solos com mesmo material de origem) (Figura 3). Os maiores teores de $\mathrm{Gb}$ do solo 2 , que foram responsáveis por seu posicionamento no quadrante inferior esquerdo, pode ser atribuído ao retrabalhamento dos sedimentos incorporados ao perfil (solo alóctone), o que favoreceu a remoção de $\mathrm{Si}$ e a formação desse mineral. Não há evidências morfológicas de sedimentação nos solos 1 e 3 (autóctones).

A intensa interferência das atividades de mineração e metalurgia de $\mathrm{Pb}$ nos solos 4 e 5 também promoveram diferenças mineralógicas nas camadas amostradas: grande dispersão das amostras $0-10,10-20$ e $20-40 \mathrm{~cm}$ de um mesmo solo. As amostras dos solos 4 e 5 agruparam-se na porção inferior devido aos maiores teores de $\mathrm{Gb}$ e Gt (Tabela 4 - Figura 3). A dispersão da amostra 4C $(20$ a $40 \mathrm{~cm})$ em relação às demais amostras desse solo para o quadrante esquerdo foi a ocorrência de $\mathrm{Hm}$ apenas na camada mais profunda. Já as amostras mais profundas do local 5 apresentaram deslocamento para a esquerda devido aos maiores teores de $\mathrm{Gb}$ (cerca de $10 \mathrm{~g} \mathrm{~kg}^{-1}$ maior do que o da amostra mais superficial - Tabela 4).

O horizonte $\mathrm{C} 2$ do solo 8 , além de apresentar maior teor de argila (Tabela 2 e Figura 2), também se diferenciou das amostras mais superficiais desse solo, por apresentar resíduo de hematita (deslocamento para a parte superior do gráfico - Figura 3).

$O$ efeito do material de origem na mineralogia da fração argila ficou evidente na separação das amostras do solo 6 (quartzito), que se distanciou dos solos formados de rochas carbonáticas/complexos granitóides.

Nos solos 4, 5 e 8 os horizontes mais superficiais apresentaram tendência ao agrupamento (Figura 3), devido aos maiores teores de Gt (Tabela 4), favorecidos pelos maiores teores de CO (Tabela 2) (Schwertmann, 1991).

\section{CONCLUSÕES}

1) $\mathrm{Na}$ área de estudo, a análise por componentes principais (ACP) foi eficiente para verificar as similaridades (agrupamento) ou as diferenças, com base na granulometria e características químicas e mineralógicas, de amostras de solos de ambientes próximos e formados de diferentes materiais de origem e submetidos a variados graus de interferência antrópica.

2) ACP da granulometria e das características químicas: devido à homogeneidade dos perfis, a profundidade de amostragem (horizonte e camadas até $40 \mathrm{~cm}$ ) não foi importante no agrupamento das amostras. O material de origem definiu a divisão das amostras em dois grandes grupos, por sua forte influência nos teores de argila e nos valores de $\mathrm{pH}$. Apenas nos solos com maior interferência antrópica a intensa incorporação de rejeitos da metalurgia de metais pesados nos perfis superou o efeito do material de 
KUMMER, L. et al. Uso da análise de componentes principais...

origem na ACP. Com relação aos processos pedogenéticos, os diferentes níveis de adição natural de matéria orgânica foram mais importante que a incorporação de sedimentos via colúvio nos perfis na separação de grupos homogêneos de amostras.

3) ACP dos atributos mineralógicos da fração argila: os teores de hematita, se contrapondo aos teores de goethita, mais os teores gibbsita, foram preponderantes para o agrupamento das amostras. Apenas dentro do quadrante de amostras com maiores teores de hematita, a variação nos teores de caulinita foi importante para a subdivisão de grupos de amostras mais homogêneos. Solos com diferentes graus de desenvolvimento (Neossolos e Cambissolos) apresentaram mineralogia similar e não foram separados pela ACP. A intensa interferência antrópica também influenciou a mineralogia das amostras de solos. Diferente da ACP para a granulometria $e$ características químicas, as amostras do solo alóctone (incorporação de sedimentos de colúvio) foram separadas em um grupo homogêneo e distinto por apresentarem maiores teores de gibbsita.

\section{REFERÊNCIAS}

1. BARBAR, L. C.; MELO, V. F. Variabilidade das características químicas e mineralógicas de solos da região metropolitana de Curitiba (PR). Scientia Agraria, v. 9, n. 2, p. 187-197, 2008.

2. BARROS, Y. J. et al. Teores de metais pesados e caracterização mineralógica de solos do cemitério municipal de Santa Cândida, Curitiba (PR). Revista Brasileira de Ciência do Solo, v. 32, n. 4, p. 1763-1773, 2008.

3. BORUVKA, L.; KOZAK, J. Geostatistical investigation of a reclaimed dumpsite soil with emphasis on aluminum. Soil and Tillage Research, v. 59, n. 3-4, p. 115-126, 2001

4. CARVALHO JUNIOR, W. C. et al. Análise multivariada de Argissolos da faixa Atlântica Brasileira. Revista Brasileira de Ciência do Solo, v. 32, n. 5, p. 2081-2090, 2008.

5. EMBRAPA - EMPRESA BRASILEIRA DE PESQUISA AGROPECUÁRIA. Manual de métodos de análise de solo. 2. ed. Rio de Janeiro: Centro Nacional de Pesquisa de Solos, 1997. $212 p$

6. EMBRAPA - EMPRESA BRASILEIRA DE PESQUISA AGROPECUÁRIA. Sistema brasileiro de classificação de solos. Rio de Janeiro: Centro Nacional de Pesquisa de Solos, 2006. 306 p.

7. GELADI, P. et al. Principal component analysis on multivariate images. Chemometrics and Intelligent Laboratory Systems, v. 5, n. 3, p. 209-220, 1989.

8. GHIDIN, A. A. et al. Toposseqüências de Latossolos originados de rochas basálticas no Paraná. I-Mineralogia da fração de argila. Revista Brasileira de Ciência do Solo, v. 30, n. 2, p. 293-306, 2006

9. GOLOBOĖANIN, D. D. et al. Principal component analysis for soil contamination with PAHs. Chemometrics and Intelligent Laboratory Systems, v. 72, n. 2, p. 219-223, 2004.

10. IPARDES - INSTITUTO PARANAENSE DE DESENVOLVIMENTO ECONÔMICO E SOCIAL. Anuário estatístico do Estado do Paraná 2005. Disponível em: <http://www.pr.gov.br/ipardes/publicacoes/anuario/anuario_2005/index.html> Acesso em 05 fev. 2008.

11. KÄMPF, N.; SCHWERTMANN, U. The $5 \mathrm{M}-\mathrm{NaOH}$ concentration treatment for iron oxides in soils. Clays and Clay Minerals, v. 30 , n. 6, p. 401-408, 1982

12. KITCHEN, N. R.; HAVLIN, J. L.; WESTFALL, D. G. Soil sampling under no-till banded phosphorus. Soil Science Society of America Journal, v. 54, n. 8, p. 1661-1665, 1990.

13. LAGES, S. G. Análise pedológica aplicada à identificação de descontinuidades estratigráficas: vertentes do córrego do Quebra, Depressão de Gouveia, MG. 2005. 100 f. Dissertação (Mestrado) - Universidade Federal de Minas Gerais, Belo Horizonte, 2005.

14. McKEAGUE, J. A. Manual on soil sampling and methods of analysis. Ottawa: Canadian Society of Soil Science, 1978. $212 \mathrm{p}$.

15. MEHRA, O. P.; JACKSON, M. L. Iron oxide removal from soils and clay by a dithionite-citrate system buffered with sodium bicarbonate. Clays and Clay Minerals, v. 7, n. 2, p. 317-327, 1960.

16. MELO, V. F. et al. Características dos óxidos de ferro e de alumínio de diferentes classes de solos. Revista Brasileira de Ciência do Solo, v. 25, n. 1, p. 19-32, 2001a.

17. MELO, V. F. et al. Chemical and mineralogical properties of kaolinite-rich Brazilian soils. Soil Science Society of America Journal, v. 65 , n. 4, p. 1324-1333, 2001b.

18. NORRISH, K.; TAYLOR, M. The isomorphous replacement of iron by aluminium in soil goethites. Journal of Soil Science, v. 12, n. 12, p. 294-306, 1961.

19. OLIVEIRA, M. A. F et al. Caracterização isotópica de metabasitos e anfibolitos dos grupos Açungui e Setuva na porção sul da faixa Ribeira. Geologia USP Série Científica, v. 2, p. 161-170, 2002.

20. SANTOS, J. S. et al. Estudo da mobilização de metais e elementos traços em ambientes aquáticos do semiárido brasileiro aplicando análises de componentes principais. Química Nova, v. 31, n.5, p. 1107-1111, 2008

21. SCHULZE, D. G. The influence of aluminium on iron oxides VIII. Unit-cel dimension of Al-substituted of goethites and estimation of Al from them. Clays and Clay Minerals, v. 32, n. 1, p. 36-44, 1984.

22. SCHWERTMANN, U. et al. The influence of aluminum on iron oxides. Part II. Preparation and properties of Alsubstituted hematites. Clays and Clay Minerals, v. 27, n. 2, p. 105-112, 1979.

23. SCHWERTMANN, U. Solubility and dissolution of iron oxides. Plant and Soil, v. 130, n.1, p. 1-25, 1991

24. SINGH, B.; GILKES, R. J. Concentration of iron oxides from soil clays by $5 \mathrm{M} \mathrm{NaOH}$ treatment: The complete removal of sodalite and kaolin. Clay Minerals, v. 26, n. 4, p. 463-472, 1991.

25. SPLECHTNA, B. E.; KLINKA, K. Quantitative characterization of nutrient regimes of high-elevation forest soils in the Southern coastal region of British Columbia, Canada. Geoderma, v. 102, n. 1, p. 153-174, 2001

26. TORRENT, J.; CABEDO, A. Sources of iron oxides in reddish brown soil profiles from calcarenites in Southern Spain. Geoderma, v. 37, n. 1, p. 57-66, 1986. 
KUMMER, L. et al. Uso da análise de componentes principais...

27. UFPR - UNIVERSIDADE FEDERAL DO PARANÁ. Manual de diagnostico da fertilidade e manejo dos solos agrícolas. 2. ed. Curitiba: Universidade Federal do Paraná, 2003. $143 p$

28. URENIUK, G. Os recursos hídricos da Bacia do Rio Ribeira de Iguape e do Litoral Sul. In: SECRETARIA DO MEIO AMBIENTE DE SÃO PAULO (Ed.). Programa de educação ambiental do Vale do Ribeira. São Paulo, 1992, p. 119145.

29. VALLADARES, G. S. et al. Análise dos componentes principais e métodos multicritério ordinais no estudo de organossolos e solos afins. Revista Brasileira de Ciência do Solo, v. 32, n. 1, p. 285-296, 2008

30. WHITE, A. F.; BRANTLEY, S. L. Chemical weathering rates of silicate minerals: An overview. Reviews in Mineralogy, v. 31, n. 1, p. 1-22, 1995.

31. WOLLENHAUPT, N. C. et al. Mapping soil test phosphorus and potassium for variable-rate fertilizer application. Journal of Production Agriculture, v. 7, n. 4, p. 441-448, 1994

32. WOWK, G. I. T.; MELO, V. F. Avaliação do nível de chumbo, em solo de várzea, proveniente da reciclagem de bactérias. Revista Brasileira de Engenharia Agrícola e Ambiental, v. 9, n. 4, p. 613-622, 2005.

Recebido em 18/05/2010

Aceito em 14/12/2010 